\title{
Urban planning measures for solar optimisation
}

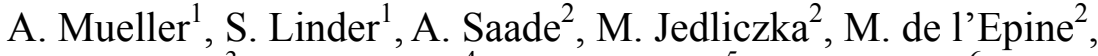 \\ E. Willdbrett ${ }^{3}$, E. Kjellsson ${ }^{4}$, A. Cornander ${ }^{5}$, J. Fernandes ${ }^{6}$, \\ R. Arndt ${ }^{7} \&$ S. Pintarits ${ }^{7}$ \\ ${ }^{1}$ Ecofys GmbH, Germany \\ ${ }^{2}$ HESPUL, France \\ ${ }^{3}$ Local Energy Agency (ALE) of Grand Lyon, France \\ ${ }^{4}$ University of Lund, Sweden \\ ${ }^{5}$ Skane Energy Agency, Sweden \\ ${ }^{6}$ Lisboa Enova, Portugal \\ ${ }^{7}$ City of Munich, Germany
}

\begin{abstract}
When a city develops an urban plan of a new area or the retrofitting of an existing one, the choices made and the infrastructure created are long term and lasting (minimum 50 years). The optimisation of solar gains is therefore a major issue as it has an impact on energy consumption and on the quality of life for residents (natural sunlight levels). In France, the Grand Lyon local energy agency (ALE) and HESPUL, are working on the optimisation of solar considerations within the urban planning process of a new urban area. In Germany, building on the experiences by the city of Munich, ECOFYS is working with several departments of the city council to set up guidelines for solar urban planning. The guidelines will afterwards serve for each new urban planning project in the city. In Lisbon, the rehabilitation project of an existing area is underway. Energy consumption targets have been decided for this area. The project area is mainly social housing and a new study into the integration of solar technologies to the area is ongoing. In Sweden, the same kind of project is developed in Malmö where an area called "Sege Park" is undergoing retrofitting measures and new developments with a green profile. Malmö City Council is
\end{abstract}


working on the legislative aspects to introduce solar requirements in the new Master Plan of the area. These experiences are presented in the following paper. Keywords: solar urban planning, solar development, passive solar gains, solar energy supply, solar mobilization, improvement of planning process.

\section{Introduction}

To assure the ability of new structures to include a solar energy supply, certain requirements need to be included in development planning and building legislation. Actors and procedures in the planning process are missing a detailed knowledge of solar pre-requirements including density, levels and orientation. Most of the time, the process is complex and different stakeholders are involved. Therefore, energy aspects is only one of many criteria that urban planners must consider in the planning process. It is important to identify how and where to introduce mandatory solar criteria in such a way as to function within the global process.

Within the framework of a cooperation project POLIS, six European cities (Munich in Germany, Lisbon in Portugal, Paris and Lyon in France, VitoriaGasteiz in Spain and Malmö in Sweden) have committed to long-term strategies to integrate solar energy at an urban level. These strategies are consistent with existing $\mathrm{CO} 2$ mitigation targets in Solar Action Plans embedded in local planning tools.

The main goal of the project is to define possible measures in diverse planning areas connected to general renewable energy targets. A strategic approach by the municipality is necessary to enhance the increased integration of small-scale, decentralized energy applications into the built environment.

Diverse approaches have been conducted in 4 different cities (Lyon, Munich, Lisbon and Malmö) and are presented below.

\section{Lyon conurbation (France), solar optimisation for urban planners}

The development of the "Lyon Confluence" project (supported by the EUfunded Concerto programme) has made urban developers think differently about energy aspects within urban design. However, many aspects could have been better integrated in the Confluence project: energy considerations were not introduced early enough and the urban planning could be more appropriate to solar criteria.

In order to follow-up on the experience of the Lyon Confluence project, Hespul and the local energy agency of Grand Lyon decided to work on the optimisation of the process of urban planning, in order to better introduce solar compatibility criteria. The figure below shows the general process of an urban planning project in France and the possible measures a city can undertake in order to optimize solar irradiation considerations:

At local authority level, work on optimisation of the urban design of a specific new development area was set up with the Grand Lyon. The main 
objective was to experiment urban planning methodologies that take into account solar radiation (natural light and heating) as an important criteria for planning. The planning area concerned by this study is situated in Bron (city member of Lyon conurbation) and is planned to be restructured into a new district. The surface of the zone is about 3 ha on which will be constructed almost 540 housing units.

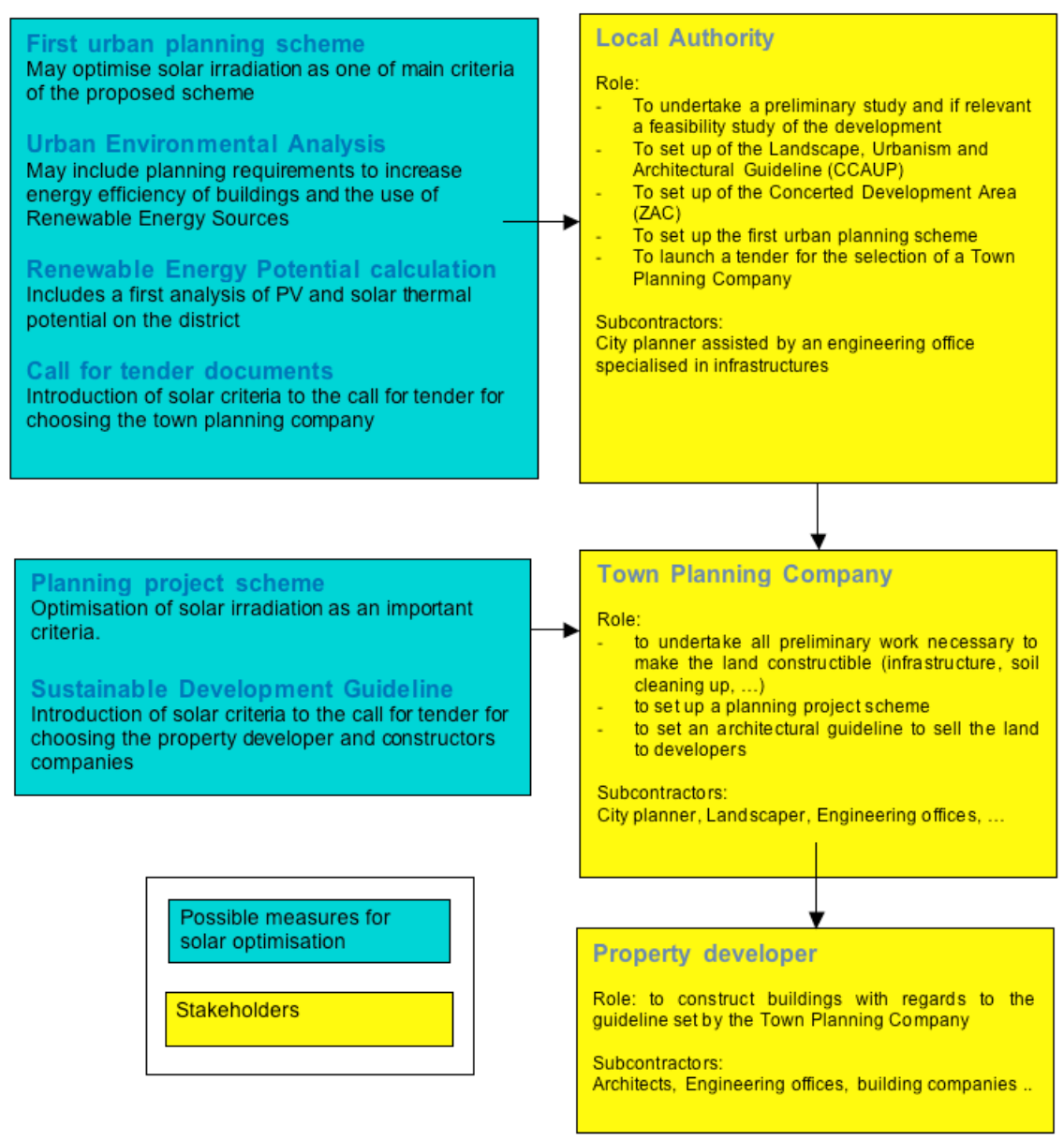

Figure 1: $\quad$ Urban planning process in France.

An initial study has been done by the Grand Lyon and produced a first urban planning scheme. This first master plan has served as a base for the optimisation study. The results will serve as an example for the town planning candidates that will reply to the call for tenders on the design and town planning of the area.

It is difficult to know at this stage the precise reduction of heating needs through the optimization of urban design, as the final consumption will depend 


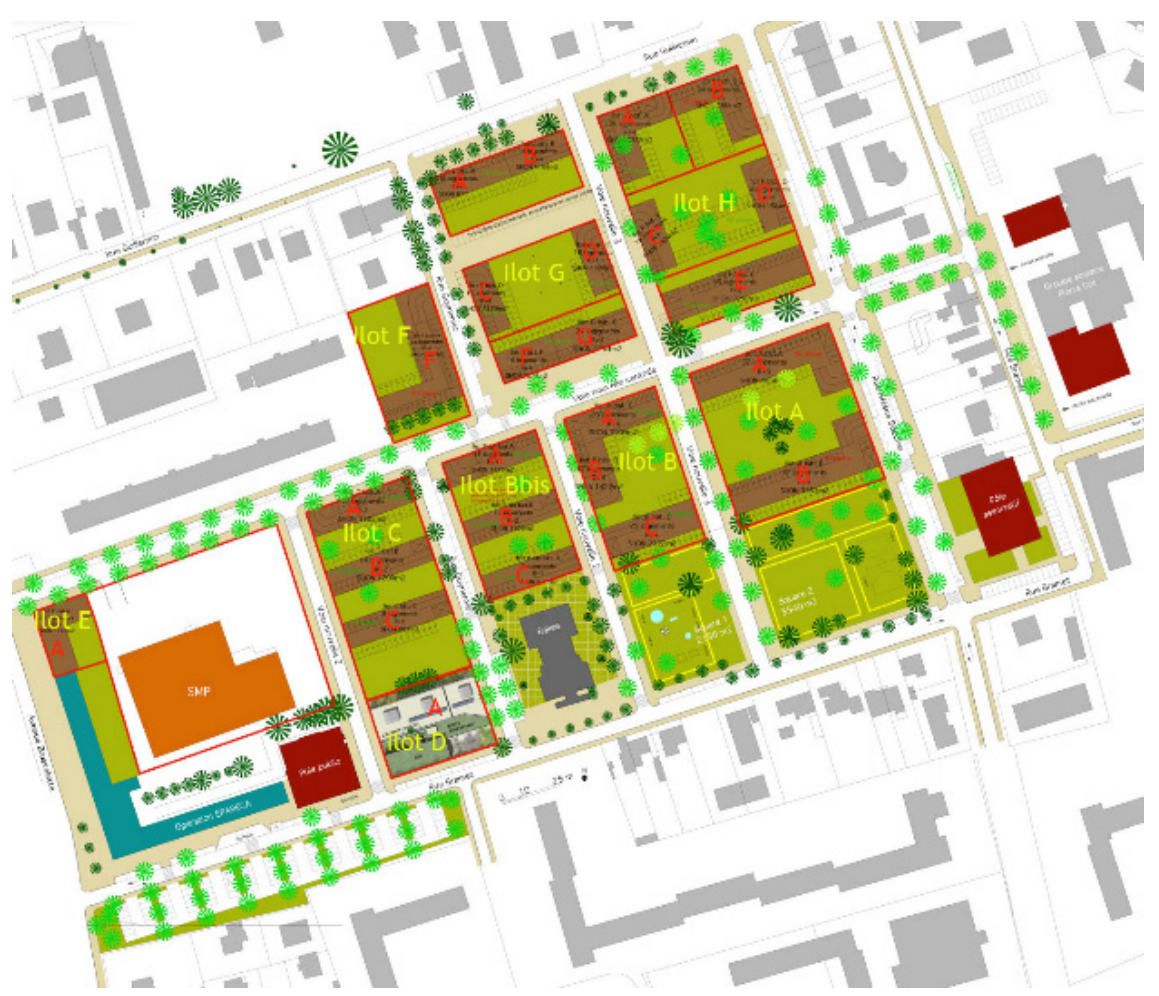

Figure 2: Original master plan of the "Bron Terraillon" area.

on the design and construction of future buildings of the area. The results of the study were limited to the evaluation of the amount of solar irradiation getting to each building in each of the urban planning scenarios.

Minimum and maximum heights for each plot were already defined by the local urbanism plan and the density objectives to be reached. It has been considered that all the buildings surrounding the area have at a maximum 2 levels. Therefore, they will not have a big impact on shadowing the solar irradiation and haven't been taken into consideration for the simulations.

The optimisation of solar potential has been done considering only heating demands and not cooling needs in the summer time.

As this kind of approach is very uncommon in France, a first step consisted on a comparison between different existing software that could be used for the solar optimisation:

- GOSOL: German language software, urban planning oriented.

- ECOTECT: English language software, building energy saving orientated.

- URSOS: Spanish language software, urban planning orientated, free.

- PLEIADES: French language software, building energy saving orientated. 
Following this comparison, one of the main conclusions stated that there was a lack of urban planning orientated software available on the market. Few offers exist and most software is appropriate to all European countries or exist in only the national language where they have been designed (German, Spanish...).

For several reasons, the French software PLEIADES has been chosen for this study. This tool is already used by architects and promoters and can be easily understood by the main stakeholders. Simulations were done during the heating period (from $15^{\text {th }}$ of October to the $15^{\text {th }}$ of April). In addition to PLEIADES, some simulations have been done with ECOTECT software.

Within the simulation, and considering the importance of shading, some plots have been first considered as "critical": see plots G and $\mathrm{H}$ below.

One of the main issues was to ensure that the living environment for residents remained a priority in the urban planning process. Some more "solar" friendly designs affected the architectural quality of the urban projects too greatly to be retained (example: centre plots in the middle of buildings used as garden includes buildings badly orientated).

The risks of overheating in summer were not taken into account in the study. It was decided to restrict this aspect design on a building level (done by the promoter or the architect).

Based on this study, a new urban plan (modified building position, lowered building heights in specific locations...) was completed and submitted to the Grand Lyon local council. This new urban plan proposition will be annexed to the call for tenders as an example for candidates. Candidates will have to justify their project considering solar aspects.

\section{Munich (Germany), development of a "solar guideline for urban planning" and pilot project}

The City of Munich has committed itself to meet climate protection targets as agreed in various initiatives. Main targets related to solar energy are the coverage of local electricity demand by $10 \%$ through photovoltaic installations within the urban area of Munich by 2015. This should be reached through the foundation of the Solar Initiative Munich (SIM) in 2010 programme. Moreover, the local electricity supplier the Stadtwerke Munich committed themselves to covering $100 \%$ of the local electricity demand by renewable energies by 2025 .

The successful implementation of these targets via the SIM requires urban development and planning actors to get involved in solar energy planning as well. There is a need for knowledge of tools and methods able to integrate important aspects of solar energy into planning practice to support the large-scale implementation of solar in the urban environment. Within the framework of the POLIS project various urban planning instruments are currently under development to complement activities concerning Munich's "Solar Initiative" (SIM). While SIM focuses on photovoltaics for certain types of buildings, all kinds of solar applications are covered by POLIS. Therefore, POLIS will in addition deal with solar thermal and passive solar applications. 
During workshops within Munich's planning department the decision was taken to develop a guideline with real standards, indicators, and measures to support the relevant parties involved in planning procedures. The aim of this guideline is to help identify opportunities for solar urban development and to create a common basis for communication with other departments, stakeholders and decision-makers. By using specific indicators for solar urban planning the degree of solar energy use can be measured and targets for solar optimized planning can be agreed upon and effectively embedded in daily planning practice.

\subsection{Approach and methodology}

Existing urban planning tools in Munich have been assessed to check whether they are suitable for the integration of solar design requirements. After this, the local POLIS working group began developing recommendations to improve these tools. Options for obligatory standards and policy incentives are being identified within the existing urban planning process in Munich. For the guideline, the various measures are grouped by topic. Already identified topics in Munich are:

- Urban competitions for new development areas. Definition of criteria and other instruments, first to include solar requirements in tendering, secondly to support jury members in their assessment of solar aspects in submitted projects and thirdly to provide basic know-how for the drafting of council resolutions for the implementation of solar planning in new development areas.

- For development areas with more than 500 apartments a city council resolution for solar energy assessment (SOLENOP) is already in effect in Munich. POLIS proposes to develop flexible instruments to improve the implementation of the outcome of this solar energy optimization in the process of weighing of interests for the final layout.

- Analysis and compilation of planning tools to facilitate the SIM through urban planning (detailed analysis of solar potentials, selection of feasible surfaces, incentives to install PV for owners, analysis of possible barriers from the urban planning point of view, identification of priority areas/suitable settlement structures).

- Criteria for the sale of municipal real estate to implement solar architecture. The already existing Catalogue of Ecological Criteria could be extended to include criteria for solar energy use (e.g. solar thermal applications to comply with existing national law (EEWärmeG). Requirements specified in this regulation can become part of urban contracts and other binding agreements.

- To mobilise solar energy use in existing buildings, incentives and information campaigns on solar thermal and photovoltaic systems could be increased with regard to urban regeneration and refurbishment.

- Integrating the POLIS pilot actions into the process of the creation of general energy plans, and for specific aspects as part of land use planning (Energienutzungsplanung/Beipläne zur Flächennutzungsplanung).

Since the planning process is quite complex and it takes a long time from the first preliminary studies to the final implementation of the buildings, the POLIS 
project aims at providing background information and advice for city planners through guidelines, and at highlighting the options for the inclusion of solar urban planning aspects.

The development area of "Bayernkaserne" has been chosen as a pilot area for more concrete activities of urban planning within the framework of POLIS.

\section{Urban Planning Process - Munich/Germany}

\section{POLIS focus activities}

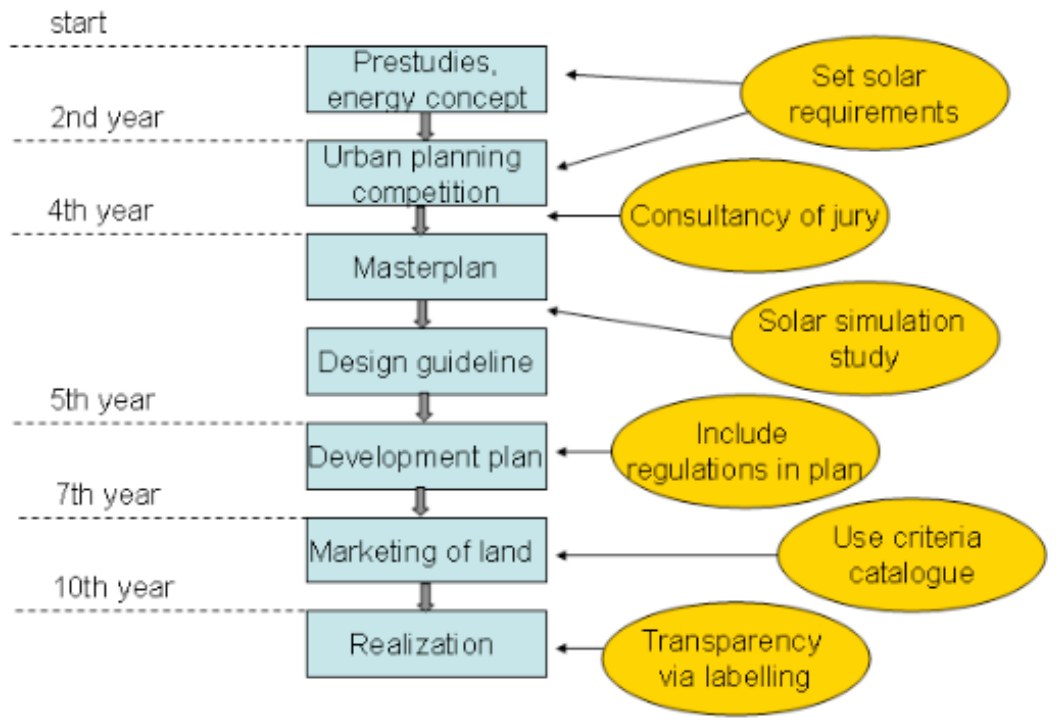

Figure 3: $\quad$ Urban planning process and POLIS activities in Munich.

\subsection{Implementation of solar aspect within pilot area Bayernkaserne}

A new solar development area was chosen by the local working group in Munich. Diverse instruments developed within the planning guidelines will be applied within the framework of the urban development project "Bayern Kaserne", a new residential area planned on a former military precinct in the center of Munich. The basics for solar urban planning will be put into practice.

In preparation of the regular urban competition for Bayern Kaserne in 2012 two external consultants have been assigned to advise and assist the City of Munich with an overall sustainability concept for this area. POLIS partner Ecofys will support the office on solar planning aspects. The next step within POLIS will be to define solar requirements for the urban competition together with the sustainability and energy adviser. A kick-off workshop in Munich is planned for February 2012 to start work on this pilot. 


\section{Lisbon (Portugal), evaluation of potential to integrate solar technologies in Boavista neighbourhood}

The Boavista Neighbourhood is a social housing area that is presently conducting an operation to refurbish and revitalize the area within an Eco Neighbourhood programme, financed by a national funding programme. The project for the neighbourhood considers two distinct approaches: the requalification of the newest part of the neighbourhood and the definition of a new urban plan for the reconstruction of the oldest area of the neighbourhood.

The re-qualification of the newest area, approximately 20 years old, consists of interventions to qualify the public space, refurbish some of the existing buildings, taking into account the energy optimization of and the integration of solar technologies both for the decentralized production of electricity with photovoltaic systems and for the production of hot water in public buildings using solar thermal systems.

The qualification of the public space includes interventions on the public lighting system and promoting the adoption of more efficient systems, such as LED lights and daylight control.

The goal in the proposal for refurbishing the existing residential buildings addresses structural and indoor comfort levels, promoting an increase in buildings energy efficiency, improving facade insulation with ecological external insulation systems that provide extra inertia to the walls and reduce the energy demands inside dwellings. The insulation materials include lime cement with cork agglomerations, an ecological material that presents both excellent thermal and insulation properties. Extra insulation gives houses the capacity to retain solar gains and reduces the demand for air conditioning.

Renewable energy technologies promote decentralized energy production and helps to ensure that a certain percentage of the local energy demands are met by local energy production systems. Existing residential buildings were evaluated so as to determine those with the best potential for solar photovoltaic systems, taking into account the roof cover's potential but also the social context of the neighbourhood. The analysis concluded that seven micro-generation systems, each with $3,68 \mathrm{kWp}$ can be installed in the area for a total of $25 \mathrm{kWp}$. Another approach is to integrate PV into a new services building, using the PV panels both as construction and as energy production material, following the BiPV concept. The building is to provide support to the management of the area's public space and is to integrate a total power of $3 \mathrm{kWp}$. Since it's a service building with hot water needs, a small solar thermal system, 2 sqm is also foreseen. As for the neighbourhood's sports facilities, a solar thermal system is to be installed in the public swimming pool, 200 sqm providing $30 \%$ of the hot water needs for the pool and daily showers.

Just as a competition will decide the new urban plan for the reconstruction of the oldest part of the neighbourhood the concept of a competition was embraced. Combing efforts to promote both an inclusive design to the neighbourhood, addressing the challenges of the urban space, energy use and the community, and fostering knowledge transfer from experienced professionals to those with little 


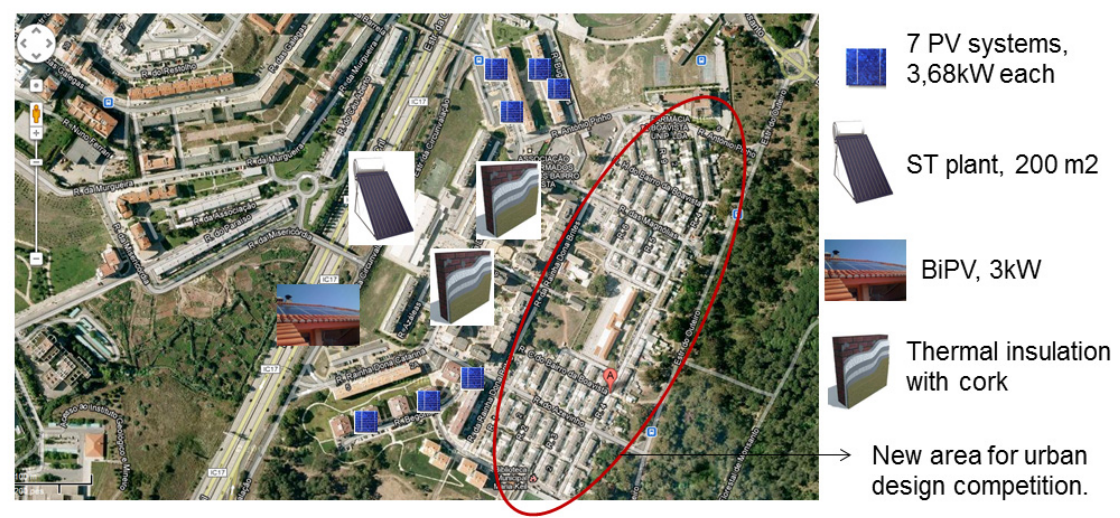

Figure 4: Global approach to the Boavista neighbourhood.

or no experience in the field, interested in learning more about solar urban planning. The integration of solar criteria into the built environment, both in terms of passive and active solar technologies, must not only promote the use of solar materials but also create an added value to the local built environment, in a synergic combination of form and function. The objective is to provide competitors technical support on solar urban planning practices and invite them to present innovative proposals that not only maximize the new area's potential to use solar technologies, but also visually communicates this "solar neighbourhood" character to the population. This Eco Neighbourhood will in this sense serve the triple purpose of technological demonstration site, pro-active dissemination of solar in the urban environment and education both at the professionals and the community level, targeting several stakeholders, from the local community to public authorities.

\section{Malmö (Sweden), urban planning in Sege Park}

Sege Park is an area undergoing retrofitting measures and new developments with a green profile, including plans and possibilities for solar energy as well as other renewable energy sources. Malmö City Council is interested in introducing solar requirements in the new local plan of the area, which would enable the installation of solar energy facilities. This is the first time this concept is to be used in Malmö.

The local working group of the POLIS project in Malmö (with representatives from the Urban Planning Department, the Environment Department, the Real Estate Office and the Department of Internal Services in collaboration with the Swedish partners in POLIS), suggested changes in the original draft of the new local plan for the area. The purpose with the suggestions was to formulate the new local plan in a way that future solar installations are facilitated; including specification of the orientation of houses and of where and in what way solar energy plants can be installed. 
The second draft of the local plan which went on public exhibition during 2011, did not take in to account all suggestions from the local working group, but it included a formulation that allows integrated solar installations in the buildings:

"The land may be developed with smaller technical solutions (thermal collectors or other installations for energy or environmental improvements) integrated in the design of the building." See figure of the local plan below.

In the end of 2011 however, the local plan that had been on public exhibition was stopped by the Malmö City Council. A decision was taken to develop a new, more ambitious local plan for the area that includes more sustainability aspects and a larger area than the original suggestion. The area will also get a higher level of development than originally suggested. The suggestions made by the working group of the POLIS project in Malmö have encouraged politicians to wish for more ambitious goals in the new development of the area.

A program for an upcoming design competition for selected architects is currently being planned. The new local plan for the Sege Park will therefore be delayed, as compared to the original time schedule, but the solar energy and sustainability ambitions in the new plan will be much higher than within the second draft of the local plan.

Once in force, the new local plan in the Sege Park area will constitute a model plan for future urban planning in Malmö as well as in other municipalities (possibly also in other countries with similar legislation).

\section{Conclusion}

Urban planning processes are very different from one country to another. The work done within POLIS project shows that several aspects are common to the different experiences and must be considered. On the other hand, some barriers to the introduction of solar aspects into planning projects remain. The remaining barriers can be summarised in three categories:

Technical aspects: Very little software for solar optimisation on an urban scale exists. Some software is not available in English and some are very expensive. However, having the right tool available is not enough as stakeholders must be trained on their use. It is important that new tools become available, as well as special trainings for urban planners.

Economical barriers and cost benefits: Introducing new criteria to the urban planning process is very often seen as a waste of time and money. Much of the software available is expensive and the time spent to understand how to use them or how to use the tools can be long. It is therefore important to consider this factor when proposing to a local authority or to a town planning company to consider solar criteria in their studies.

Social aspects: most urban planners consider that solar aspects are only related to building design (developer level) and therefore do not want to introduce solar criteria to their planning scheme study. Introducing new criteria and new methodologies are only accepted with difficulty as they change the usual working methods. As it is difficult to propose concrete solutions to this 
kind of barrier, it is important that they be evaluated and understood for each new project.

\section{References}

[1] Fernandes J., 2009. MSc Thesis The potential for BIPV Product Development and Entrepreneurship in Portugal Evidence from the International Design Competition Lisbon Ideas Challenge", Technical university of Lisbon

[2] Munro D., Gaidon B., Kaan H. 2009, Photovoltaics in the urban environment lessons learnt from large scale projects. Earthscan

[3] Suberlyme ${ }^{\circledR}$ ECO-ETICS Isolamento Térmico de Fachadas pelo Exterior.2011. www.suberlyme.com

[4] POLIS project: www.polis-solar.eu

[5] Agence Locale de l'Urbanisme de l'agglomération grenobloise, Energie et Urbanisme 